\title{
Air pollution and life expectancy: is there a relation?
}

\author{
Bert Brunekreef
}

The great smog disasters of the past have made clear that air pollution can kill people in a matter of days: extremely high concentrations of air pollution building up under conditions of low wind speed and stable atmospheric conditions have been associated with excess deaths in the Meuse Valley, Belgium (1930); Donora, PA, United States (1948); and London, United Kingdom (1952). In the developed market economies, great efforts have since been made to curtail air pollution related to the use of fossil fuels such as coal and oil, and exposures to substances such as $\mathrm{SO}_{2}$ and soot have been dramatically reduced. For a while it was thought that ambient concentrations of air pollution had become so low as to have no discernible influence on mortality or morbidity in the population any more. However, a series of recent studies have shown that even at low concentrations of substances-such as ozone and fine particulate matter in air-day to day variations in mortality, respiratory and cardiovascular hospital admissions, symptom exacerbations among asthmatic patients, lung function in schoolchildren, etc are still associated with day to day changes in concentrations of air pollution. ${ }^{1}$ Although such findings are important in their own right, they do not directly prove that long term exposure to air pollution at present levels in the developed market economies increases the prevalence of (chronic) diseases in the population, possibly leading to decreased survival and hence, reduced life expectancy: the associations found between day to day variations in mortality and air pollution may, for example, represent a "harvesting" effect-that is, an advancement of death by a few days or weeks in subjects already about to die from other causes anyway. Clearly, such effects would not lead to discernible effects of long term exposure to air pollution on life expectancy in the population. There is some evidence, however, that long term exposure to relatively low concentrations of ambient air pollution leads to a measurable reduction of survival in the population. In this paper, I briefly review the evidence, focusing on effects of airborne particulate matter, and I provide a simple estimate of the effect that long term exposure to air pollution may have on life expectancy, based on this evidence.

Environmental and

Occupational Health,

University of

Wageningen

B Brunekreef

Correspondence to: Dr Bert Brunekreef, PO Box 238, $6700 \mathrm{AE}$ Wageningen, The Netherlands.

Accepted 27 May 1997 cohort studies documenting the mortality experience of differentially exposed subjects over time.

An example of a cross sectional analysis of the association between mortalities and airborne particulate matter is a study by Özkaynak and Thurston. ${ }^{2}$ They compared United States mortalities in 1980 with various measures of exposure to airborne particulate matter. In this analysis, sulphates, fine particles, inhalable particles, and total suspended particles were found to be associated, in decreasing order, with total mortality, after adjustment for several socioeconomic predictors of mortality. A recent example from Europe is a study reported by Bobak and Leon from the Czech Republic. $^{3}$ These authors correlated infant mortality with air pollution by particulate matter over the years 1986-8. Annual geometric mean particle concentrations were $68.5 \mu \mathrm{g} / \mathrm{m}^{3}$ overall. Concentrations were subdivided into quintiles, the highest relating to areas with annual mean particle concentrations $>84.7$ $\mu \mathrm{g} / \mathrm{m}^{3}$. After adjustment for several socioeconomic indicators, illegitimate pregnancies and abortion rate, and $\mathrm{SO}_{2}$ and $\mathrm{NO}_{\mathrm{x}}$, postneonatal mortality were found to increase almost monotonically with particle concentrations, the highest quintile having a relative risk of 1.42. The estimated risk ratios were higher for postneonatal respiratory mortality. Particle concentrations were reported as particulate matter with a diameter $<10 \mu \mathrm{m}\left(\mathrm{PM}_{10}\right)$.

The general criticism of such studies is that they are ecological in comparing aggregate data on mortality with aggregate data on pollution, without the possibility of taking individual confounders into account.

Recently, however, the suggestive evidence coming from the cross sectional studies has been supplemented with data from two cohort studies. Dockery et $a l^{t}$ followed up a cohort of more than 8000 adults living in six United States cities with varying levels of exposure to air pollution for periods of 14-16 years, between 1974 and 1991. After adjustment for age, sex, smoking, education, occupational exposure, and body mass index, a significant relation was found between exposure to fine particles (particles with a mass median diameter of $<2.5 \mu \mathrm{m}, \mathrm{PM}_{2.5}$ ) and survival. The closest association was found for $\mathrm{PM}_{2.5}$ and $\mathrm{SO}_{4}{ }^{2-}$, with less clear relations with TSP, PM $_{10}$, aerosol acidity (only measured for one year in each city), and $\mathrm{SO}_{2}$, and a virtually absent relation with ozone. The estimated effect was a mortality rate ratio of 1.26 , comparing the most polluted city (Steubenville, Ohio) with

the least polluted city (Portage, Wisconsin). \author{
matter on mortality come from cross sectional \\ studies comparing exposure to air pollution \\ and mortalities between locations and from \\ Mortality: effects from chronic exposure \\ as suggested by cross sectional and \\ cohort studies
}


The mean fine particle concentrations ranged from $11.0-29.6 \mu \mathrm{g} / \mathrm{m}^{3}$ with little change over the study period (fine particle measurements were reported for the $1980-8$ period). The $\mathrm{PM}_{10}$ concentrations ranged from 18.2-46.5 $\mu \mathrm{g} / \mathrm{m}^{3}$. The mortality rate ratio for men was higher (1.32) than for women (1.18). There was little difference in the rate ratios for exposure to air pollution between smokers, exsmokers, and non-smokers. Compared with, for example, the mortality rate ratio associated with active smoking in this cohort (1.59), this represents a sizeable effect of particulate air pollution on survival.

Pope et $a \bar{l}$ analysed data from a large cohort study conducted by the American Cancer Society since 1982 . Ambient air pollution data from 151 United States metropolitan areas were linked to eight years of follow up data from more than 550000 subjects. The annual mean sulphate particle concentration for the year 1980 was available for all 151 metropolitan areas, and ranged from 3.6 to $23.5 \mu \mathrm{g} / \mathrm{m}^{3}$. The median concentration of fine particles for the years 1979-83 was available for 50 metropolitan areas, with a study population of almost 300000 . The fine particle concentrations ranged from $9.0-33.5 \mu \mathrm{g} / \mathrm{m}^{3}$ between areas. After adjustment for age, sex, race, active and passive smoking, occupational exposure, education, body mass index, and alcohol intake, a significant relation between fine particulate exposure to air pollution and survival was found. Comparing the highest with the lowest polluted area, an adjusted mortality rate ratio of 1.17 was found for $\mathrm{PM}_{2.5}$ (1.18 for men, 1.16 for women). The mortality rate ratio for being a current smoker was 2.07 in this study.

In view of the estimated large magnitude of the effect of relatively low particle concentrations on survival, the results of these two studies require further scrutiny and replication. No comparable data from Europe or elsewhere are currently available. Few data exist on the concentration of fine particles in European cities. In studies conducted by us in The Netherlands, we have found mean $\mathrm{PM}_{2.5}$ concentrations of $19.6 \mu \mathrm{g} / \mathrm{m}^{3}$ were averaged over the winter months of 1994-5 in Amsterdam. Mean $\mathrm{PM}_{10}$ concentrations for the same period were $30.8 \mu \mathrm{g} / \mathrm{m}^{3}$. The measurement period was characterised by mild, wet weather. By contrast, we found much higher $\mathrm{PM}_{2.5}$ concentrations, of $39.7 \mu \mathrm{g} / \mathrm{m}^{3}$, in a village in the south west of the country during the winter of 1995-6, which was characterised by cold weather and significant transport of air pollution accross boundaries in the east. Mean $\mathbf{P M}_{10}$ concentrations measured nearby over the same period were $57.4 \mu \mathrm{g} / \mathrm{m}^{3}$. Yearly average $P M_{10}$ concentrations in The Netherlands ranged from $32.3-49.7 \mu \mathrm{g} / \mathrm{m}^{3}$ in 1993 , and from $30.7-$ $47.5 \mu \mathrm{g} / \mathrm{m}^{3}$ in $1994 .^{6}$ In the winter of $1993-4$, we coordinated a Europe wide study (the PEACE study for pollution effects on asthmatic children in Europe), in which we measured $\mathrm{PM}_{10}$ concentrations in 14 different urban areas in Europe. ${ }^{7}$ The median $\mathbf{P M}_{10}$ concentrations in the four Scandinavian sites (Umea and Malmo, Sweden, Kuopio, Finland,
Oslo, Norway) ranged from $12-21 \mu \mathrm{g} / \mathrm{m}^{3}$. In Amsterdam and Berlin they were 34 and 47 $\mu \mathrm{g} / \mathrm{m}^{3}$ respectively. In six locations in central and eastern Europe including Prague, Cracow, and Budapest median $\mathbf{P M}_{10}$ concentrations ranged from $39-63 \mu \mathrm{g} / \mathrm{m}^{3}$; high concentrations were found in Pisa, Italy $\left(57 \mu \mathrm{g} / \mathrm{m}^{3}\right)$ and Athens, Greece $\left(92 \mu \mathrm{g} / \mathrm{m}^{3}\right)$. These data show that concentrations of fine particles are at least as high, and often higher, in European cities than in the United States metropolitan areas that were studied in the two cohort studies.

To illustrate the potential impact of long term exposure to particles on mortality, the results of the cohort studies have been used to estimate the reduction of life expectancy associated with a certain difference in long term exposure to particles. On the basis of the effect estimates from both studies for fine particles, a joint relative risk (RR) of 1.10 has been assumed per $10 \mu \mathrm{g} / \mathrm{m}^{3}$ difference in long term exposure to fine particles (a difference well within the range that was actually found in the two studies). The RR of 1.10 compares with the actual RRs of 1.172 per $10 \mu \mathrm{g} / \mathrm{m}^{3}$ for the study of Dockery et $a l^{4}$ and 1.073 per $10 \mu \mathrm{g} / \mathrm{m}^{3}$ for the study of Pope et al. ${ }^{5}$ In view of the larger size of that study, ${ }^{5}$ it seems justified to let it carry more weight than that of Dockery et $a l^{4}$ (quoted estimates are for men).

In table 1, this RR estimate has been applied to the 1992 life table for Dutch men. The calculation has been restricted to ages $25-90$, as the cohort studies have not gone beyond the age of 90 (the study of Dockery et $a l^{4}$ investigated a random sample of 25-75 year olds, who were followed up for about 15 years). It is well known that in very old age, competing risks reduce the risk ratios for even strong determinants of mortality such as smoking ${ }^{8}$ so that it is not appropriate to estimate effects of particles for subjects in age ranges not actually studied.

The estimation of long term effects of air pollution on mortality in Dutch men has, for the purpose of this paper, been simplified so that it can easily be reproduced by hand:

(1) The study published by Dockery et al $(1993)^{4}$ investigated a random cohort of 25-75 year old subjects who were followed up for about $\mathbf{1 5}$ years. It is assumed that for a calculation of effects of fine particles on life expectancy, a restriction to 25-75 year olds at the start, and to the expected mortality experience of 25-75 year olds over a 15 year period is needed.

(2) To estimate the mortality experience of 25-75 year olds over a 15 year period in The Netherlands, the Central Bureau of Statistics (CBS) 1992 life table for men in The Netherlands has been used. To simplify the calculations somewhat, only the data from the midpoints of the 10 successive five-year categories that make up the $25-75$ year old age range (27.5 years, 32.5 years, 72.5 years) have been used. The expected number of deaths for each of these 10 age categories was calculated over a 15 year period by substraction of the number alive at age $n+15$ from the number alive at age $n$. 
Table 1 Estimated effect of exposure to particulate matter on life expectancy of Dutch men

\begin{tabular}{|c|c|c|c|c|}
\hline Age & Survivors (men) & $\begin{array}{l}\text { Deaths in } 15 \text { years } \\
\text { (n) }\end{array}$ & $\begin{array}{l}\text { Expected deaths in } 15 \\
\text { years in clean air }(n)\end{array}$ & $\begin{array}{l}\text { Expected survivors in } \\
\text { clean air }(n)\end{array}$ \\
\hline $\begin{array}{l}27.5 \\
32.5 \\
37.5 \\
42.5 \\
47.5 \\
52.5 \\
57.5 \\
62.5 \\
67.5 \\
72.6 \\
77.5 \\
82.5 \\
87.5\end{array}$ & $\begin{array}{l}98177 \\
97752 \\
97232 \\
96503 \\
95335 \\
93414 \\
90231 \\
84967 \\
76545 \\
64078 \\
47681 \\
29849 \\
14066 \\
\text { Total years lived: } \\
4929150\end{array}$ & $\begin{array}{r}1674 \\
2417 \\
3818 \\
6272 \\
10368 \\
16869 \\
26153 \\
37268 \\
46696 \\
50012\end{array}$ & $\begin{array}{l}\text { Life expectancy } \\
\text { between } 25 \text { and } 90 \text { : } \\
5038265 / 98359 \\
=51.22\end{array}$ & $\begin{array}{l}98177 \\
97752 \\
97232 \\
96655 \\
95555 \\
93761 \\
90944 \\
86108 \\
78369 \\
66981 \\
51756 \\
34907 \\
19456 \\
\text { Total years lived: } \\
5038265\end{array}$ \\
\hline
\end{tabular}

(3) It has been assumed that if the air contained a significantly lower concentration of fine particles, the mortality would be decreased by a factor of 1.10 . The expected number of deaths for each age category over a period of 15 years now decreases by a factor of 1.10 . This affects the number of survivors in the "clean air" category, and for simplification it has been assumed that the effect of fine particles only starts to become manifest after 15 years in subjects who were in the first five-year category initially, so that the number of survivors increases starting at age category 40-45. This point was taken into account when estimating the expected number of deaths in the clean air category.

(4) To calculate average life expectancy between 25 and 90 , the total number of years lived between 25 and 90 was calculated by multiplying the number of survivors in each of the five-year intervals (represented by the number of survivors at ages 27.5.. 87.5 years) by 5 . The result is the total number of years lived between ages 25 and 90 for men in The Netherlands. Life expectancy at age 25 is defined as the total number of years lived divided by the total number of subjects alive at age 25 (for men, 98359 out of each 100000 ).

(5) By performing this calculation for Dutch men on the basis of the 1992 CBS life table, and for the hypothetical Dutch male population exposed to a lower concentration of fine particles, the effect of fine particles on life expectancy has been estimated.

Table 2 Estimated effect of exposure to particulate matter on life expectancy of Dutch men: calculations of table 1 extended with two more 5-year age categories

\begin{tabular}{|c|c|c|c|c|}
\hline Age & $\begin{array}{l}\text { Survivors } \\
\text { (men) }\end{array}$ & Deaths in $15 y(n)$ & $\begin{array}{l}\text { Expected deaths in } \\
15 y \text { in clean air }(n)\end{array}$ & $\begin{array}{l}\text { Expected survivors in } \\
\text { clean air }(n)\end{array}$ \\
\hline $\begin{array}{l}27.5 \\
32.5\end{array}$ & $\begin{array}{l}98177 \\
97752\end{array}$ & $\begin{array}{l}1674 \\
2417\end{array}$ & $\begin{array}{ll}1522 \\
2197\end{array}$ & $\begin{array}{l}98177 \\
97 \quad 752\end{array}$ \\
\hline- & - & - & - & - \\
\hline $\begin{array}{l}67.5 \\
72.5 \\
77.5 \\
82.5 \\
87.5 \\
92.5 \\
97.5\end{array}$ & $\begin{array}{l}76545 \\
64078 \\
47681 \\
29849 \\
14066 \\
4567 \\
846 \\
\text { Total years } \\
\text { lived: } \\
4956215\end{array}$ & $\begin{array}{l}\text { Life expectancy } \\
\text { between } 25 \text { and } 100 \text { : } \\
4956215 / 98359= \\
50.39\end{array}$ & $\begin{array}{l}\text { Life expectancy } \\
\text { between } 25 \text { and 100: } \\
5104690 / 98359= \\
51.90\end{array}$ & $\begin{array}{l}78369 \\
66981 \\
51756 \\
34907 \\
19456 \\
9212 \\
4073 \\
\text { Total years lived: } \\
5104690\end{array}$ \\
\hline
\end{tabular}

(6) There is a difference of 1.11 years in life expectancy between the exposed and the clean air groups.

(7) To show how sensitive this result is to a slight extrapolation beyond the age range that was actually studied in the cohort studies, table 2 extends the calculations for another two fiveyear age groups. The result is a difference in life expectancy of 1.51 years, a $36 \%$ larger estimate than the previous one. (The calculated life expectancy of 50.39 years over the 25-100 year age span is close to the actual total life expectancy of 50.49 years given in the CBS life table for a 25 year old Dutch man, showing that the simplifications in the calculation do not lead to notable deviation from this number.)

\section{Discussion}

The calculations performed in this paper suggest that the effect of long term exposure to relatively low concentrations of fine particulate matter in air may lead to a reduction of life expectancy of more than one year. Several reservations need to be taken into account when interpreting these results.

(1) The calculations are based on the results of two prospective cohort studies. This data base is small and it is quite conceivable that the $R R$ estimates will need to be revised when more information becomes available.

(2) As in all epidemiological studies, questions remain about the two studies cited with respect to the extent to which all possible confounders were adequately taken into account. It is not the purpose of this paper to review the findings as such; this has been done already several times-for instance, extensively in the recent EPA criteria document on particulate matter. ${ }^{9}$ This document generally accepts the findings of these two studies, although it refrains from making a quantitative estimate of the potential effect of long term exposure to particles on shortening life. Yet, it acknowledges that "life shortening could conceivably be on the order of years" (pp 13-45).

(3) The results are sensitive to extrapolation beyond the age groups that were actually studied in the cohort studies, as indicated; there is also a legitimate question about whether the results are sensitive to which life table is chosen for the analysis. To investigate this, I have made a similar analysis for the life table of United States white men, 1969-71, as already published, ${ }^{10}$ which may be more representative for the United States populations studied from the mid-1970s to the late 1980 s in the two cohort studies. The result is an estimated difference in life expectancy of 1.31 yearsthat is, slightly bigger than the 1.11 year estimate for the 1992 life table for Dutch men. However, the populations studied in the two cohort studies are not necessarily representative for United States (white) men in general, and another way of comparing populations is to compare the percentage of subjects who actually were found to die in the cohort studies in the period of follow up, to the percentage estimated to die over a certain period in the hypothetical populations that make up the life tables. The study of Dockery $e t$ 
$a l^{4}$ reported 830 deaths over a 14-16 year follow up of 3668 men who were 25-75 at enrolment $(22.6 \%)$. The calculations on the basis of the Dutch 1992 life table show a death rate of $22.5 \%$ for the $25-75$ year olds, over a 15 year period. By contrast, the 1969-71 life table for United States white men shows a death rate of $26.8 \%$ over a 15 year period for the $25-75$ year olds. It seems therefore that the Dutch 1992 life table data are more comparable with the data from the study of Dockery et al than the United States 1969-71 life table. An explanation for this could be a further increase in life expectancy since 1970 in the United States; other explanations could be that the cohort that was studied was actually healthier than the population of United States white men in general; or that the age distribution was in fact different from the age distribution of the life table. In any case, it seems that the estimates from the 1992 Dutch life table agree well, in terms of expected number of deaths over a 15 year period, with the actual number of deaths that occurred in the study of Dockery et al.

(4) Is it reasonable to assume that reduction of exposure to air pollution could actually increase life expectancy by the number of years estimated in this paper? The publications on "cause elimination life tables" caution against expecting too much from elimination of single causes of death in this respect, because other, competing causes of death may actually reduce the gains expected from elimination of the cause of interest. ${ }^{11}{ }^{12}$ This discussion is usually phrased in terms of eliminating certain (chronic) diseases as cause of death, however, and the RRs used in this paper are from cohort studies in which, besides uncontrolled confounding, all competing causes of death must be assumed to have been operating concurrently with exposure to air pollution. Hence, comparing the most and least exposed populations in these studies is equivalent to estimating what the effect of a reduction of air pollution from the most to the least exposure level would be on life expectancy.

(5) The subjects in the cohort studies have been exposed to air pollution all their lives, and generally, there is no adequate quantitative information available on historical exposures. In the study of Dockery et al, concentrations of fine particulate matter were shown not to change much during the $1980 \mathrm{~s}$, but it is not known how high exposures may have been in earlier years. If the contrast in pollution-years was actually larger in these studies than the measurement data from the 1980 s suggest, the RRs expressed per unit exposure to air pollution may be overestimating the true risks, assuming that the mortality experience during the follow up period has some causal relation with exposure earlier in life.

In conclusion, effects of relatively small differences in long term exposure to airborne particulate matter on life expectancy could be substantial.

This paper is largely based on a chapter about airborne particulate matter which was written as a basis for revision of the current World Health Organisation Air Quality Guidelines for Europe.

1 Dockery DW, Pope CA III. A review of the acute respiratory effects of particulate air pollution. Annu Rev Public Healt 1994;15:101-32.

2 Özkaynak H, Thurston GD. Associations between 1980 U.S. mortality rates and alternative measures of airborn particle concentrations. Risk Anal 1987;7:449-61.

3 Bobak M, Leon DA. Air pollution and infant mortality in the Czech Republic, 1986-8. Lancet 1992;340:1010-4.

4 Dockery DW, Pope III CA, Xu X, Spengler JD, Ware JH Fay ME, et al. An association between air pollution and Fay ME, et al. An association between air pollution and
mortality in six US cities. $N$ Engl $₹$ Med 1993;329:1753-9.

5 Pope CA III, Thun MJ, Namboodiri MM, Dockery DW, Evans JS, Speizer FE, Heath CW. Particulate air pollution Evans JS, Speizer FE, Heath CW. Particulate air pollution
as a predictor of mortality in a prospective study of U.S. as a predictor of mortality in a prospective study of

6 Wal JT van der, Janssen LHJM. Description and analysis of ambient fine particle concentrations in the Netherlands. Bilthoven: RIVM (National Institute of Public Health and the Environment), 1996. (RIVM Report no 723301007 .)

7 Hoek G, Forsberg B, Borowska M, Hlawiczka S, Vaskövi E Welinder $\mathrm{H}$, et al. Wintertime concentrations of PM10 and black smoke from 28 European regions studied in the framework of the PEACE study. Atmospheric Environment 1997; (in press)

8 Doll R, Peto R, Wheatly K, Gray R, Sutherland I. Mortality in relation to smoking: 40 years' observations on male Britin relation to smoking: 40 years' 9 US Environmental Protection Agency. Air quality criteria for particulate matter. Washing

10 Elandt-Johnson RC, Johnson NL. Survival models and data analysis. New York: John Wiley, 1980.

11 Manton KG, Poss SS. Effects of dependency among causes of death for cause elimination life table strategies. Demography 1979;16:313-27.

12 Mackenbach JP, Kunst AK, Lautenbach H, Bijisma F, Oei YB. Competing causes of death: an analysis using multiplecause-of-death data from the Netherlands. Am 9 Epidemiol 1995;141:466-75. 